DOI:10.14198/ELUA2016.30.15

\title{
RAFAEL MARÍN (ed.) (2015): LOS PREDICADOS PSICOLÓGICOS. MADRID: VISOR LIBROS. 277 páginas
}

\author{
Nuria Merchán Aravid \\ Universidad de Alicante
}

La obra objeto de esta reseña constituye una monografía que recoge una serie de contribuciones acerca de un tipo de predicados lingüísticamente significativos: los predicados psicológicos. La idea central que vertebra este libro es la diversidad, tanto en los temas concretos como en los enfoques elegidos.

El volumen consta de una introducción seguida de siete capítulos asociados, cada uno de ellos, a las siete aportaciones sobre los predicados psicológicos que aúna la obra. Dichas aportaciones se plantean desde diferentes niveles de análisis (morfología, sintaxis, semántica, etc.), distintos enfoques (teórico, empírico) y diversos modelos (variantes de la Gramática Generativa, Teoría Sentido-Texto, etc.). Las cuatro primeras contribuciones se centran en los verbos psicológicos, pero las tres últimas amplían el debate abordando formas analíticas, nombres y adjetivos psicológicos.

La introducción o apartado inicial supone una explicación detallada de los conceptos teóricos trabajados a lo largo del volumen, así como una propuesta de estado de la cuestión sobre dichos conceptos, a saber: los verbos psicológicos, su estructura argumental y su aspecto verbal, las pasivas psicológicas, los participios de verbos psicológicos, los adjetivos psicológicos, los nombres psicológicos, etc. De modo general, como postula el autor de este apartado introductorio, Rafael Marín, "con el apelativo [...] de psicológicos se suele aludir a aquellos predicados que, de una forma otra, hacen referencia a la emoción o estado mental o psicológico que experimenta un individuo".

El primer capítulo está dedicado a la distinción y caracterización de los verbos psicológicos en español, los cuales constituyen una clase gramatical relevante en esa lengua, conclusión que se alcanza en dicho capítulo a través del análisis de diversas pruebas en torno a los experimentantes. En este sentido, tradicionalmente se distinguen tres clases de verbos psicológicos: verbos con experimentante nominativo y un segundo argumento acusativo (amar); verbos con experimentante acusativo y causante nominativo (preocupar); verbos con experimentante dativo y un segundo argumento nominativo (agradar). El límite entre la segunda y la tercera clase es fluctuante en español, pues se establecen alternancias entre ellas relacionadas con la eventividad del predicado. Desde una perspectiva empírica, cuando el evento psicológico designa un cambio, se usa el acusativo para expresar el experimentante;

Para citar esta reseña / To cite this book review: Merchán Aravid, Nuria (2016). Reseña de Rafael Marín (ed.) (2015): Los predicados psicológicos. Madrid: Visor Libros. ELUA, 30: 287-290. doi:10.14198/ELUA2016.30.15

Enlace / Link: http://dx.doi.org/10.14198/ELUA2016.30.15 
cuando designa un estado, se emplea el dativo. No obstante, según defiende el autor de este capítulo, Antonio Fábregas, solo algunos acusativos y solo algunos dativos de predicados "psicológicos" son experimentantes. Así, algunos acusativos conceptualmente clasificados como experimentantes de verbos psicológicos son, en realidad, pacientes de verbos de cambio de estado (ofender). Por su parte, algunos dativos conceptualmente clasificados como experimentantes son, en realidad, beneficiarios introducidos por una estructura aplicativa (olvidar). En lo concerniente a la citada primera clase de verbos psicológicos, aquellos con experimentante nominativo, se plantea que no deben ser entendidos como psicológicos, pues sus sujetos no son estructuralmente experimentantes. Como síntesis, existen los verbos psicológicos en español, pero no todos los elementos entendidos conceptualmente como miembros de esa clase pertenecen gramaticalmente a ella.

El segundo capítulo pretende, de modo general, demostrar que las propiedades especiales de los verbos psicológicos proceden de las raíces que presentan y no de las estructuras argumentales sintácticas en las que se insertan. En este sentido, es esperable encontrar una misma raíz asociada a diferentes estructuras (teoría neoconstruccionista), de manera que se destaca la elasticidad de los verbos: un mismo verbo puede encontrarse en construcciones sintácticas diferentes y, en consecuencia, de semántica estructural diferente. De manera más particular, los autores de este capítulo, Víctor Acedo-Matellán y Jaume Mateu, se centran en las Clases II y III de los predicados psicológicos. Así, constatan que en español, a diferencia de lo que se suele proponer, la lectura estativa sí es compatible con la estructura de objeto experimentante acusativo (Aquella sensación de vergüenza la ha atormentado durante mucho tiempo). Por otro lado, establecen una diferenciación entre las construcciones con experimentante dativo, tanto las de predicado simple como las de predicado complejo (verbo + sustantivo): si bien todas poseen un argumento externo dativo, su estructura argumental puede ser inacusativa estativa ( $A$ Rosa le gustan los lunares) o inergativa no estativa (A Rosa le molesta el humo; A Rosa le dan asco las ratas). De este modo, llegan a la conclusión de que la estatividad tiene un carácter epifenoménico, ya que puede relacionarse con la presencia de una coincidencia central (Aquella sensación de vergüenza la ha atormentado durante mucho tiempo; A Rosa le gustan los lunares; Rosa odia las espinacas) o con la presencia de un dativo experimentante, del que se predica una propiedad ( $A$ Rosa le dan asco las ratas).

Por su parte, la autora del capítulo tercero, Mercedes Pujalte, se centra principalmente en las Clases I (Juan detesta las acelgas) y III (A Andrés le agrada la sonrisa de Valentina) de los predicados psicológicos, aunque aborda tangencialmente la Clase II en su variante estativa (A Diego le asustan las arañas grandes $)^{1}$, todo ello desde una perspectiva sintactista. La hipótesis general se basa en que es posible unificar las clases de verbos psicológicos estativos, para lo cual se presentan dos justificaciones en torno a las propiedades compartidas. Por un lado, se propone que las construcciones psicológicas estativas constituyen estructuras subyacentemente transitivas en las que el experimentante se genera como argumento externo y el tema como argumento interno. Las diferencias observadas en la distribución del caso son consecuencia de la distribución de los rasgos flexivos sobre los núcleos funcionales de

1 La autora plantea una Clase II más abarcadora que la expuesta anteriormente, pues agrupa aquellos verbos cuyo experimentante ocupa la posición de objeto y manifiesta, alternativamente, caso acusativo (A María los empleados disfrazados la asustaron en el Tren Fantasma - versión eventiva) o dativo (A María le asustan las arañas - versión estativa). Tradicionalmente se ha observado la versión estativa de estos predicados como la verdaderamente psicológica. 
la oración. Por otro lado, se demuestra la imposibilidad extendida en los predicados psicológicos estativos de que el argumento tema se realice con nombres escuetos (no determinados), dado que siempre valúa caso estructural (nominativo o acusativo), es decir, las raíces involucradas no asignan caso inherente a su argumento interno.

El capítulo cuarto plantea como objetivo fundamental explorar la interpretación de las construcciones formadas por ser y estar con participios pasados de verbos psicológicos: se trata de indagar si se interpretan como pasivas verbales (con ser) y pasivas adjetivales (con estar), o si tienen otras características diferentes. En este sentido, los autores Berit Gehrke y Cristina Marco se sitúan en la encrucijada de dos de los temas más estudiados en la gramática del español: la interpretación de los participios pasivos, que pueden tener usos verbales y adjetivales; y la interpretación de las construcciones con ser y estar acompañadas de participios pasados y adjetivos. De este modo, llegan al cuestionamiento de las predicciones derivadas de los estudios teóricos existentes sobre la semántica y la sintaxis de los verbos psicológicos y sobre las pasivas verbales y adjetivales. Para ello se apoyan principalmente en datos cuantitativos sobre la frecuencia de aparición de estas construcciones en un corpus representativo del español del siglo XX. Así, llevan a cabo un detallado análisis del que extraen resultados y conclusiones relevantes en torno a los predicados psicológicos, por ejemplo: es posible la formación de pasivas verbales con los verbos de sujeto experimentante; se confirma la posibilidad de formación de pasivas verbales con verbos de objeto experimentante; es adecuada la afirmación de que los verbos de sujeto y dativo experimentante no pueden formar pasivas adjetivales; etc.

El quinto capítulo parte de la hipótesis de que la construcción psicológica se distingue gramaticalmente, y no necesariamente por la presencia de un predicado inherentemente psicológico. Así, la autora de este trabajo descriptivo, Ángela L. Di Tullio, comprueba que la lectura estrictamente psicológica de estos predicados depende del sujeto y, más específicamente, de su interpretación proposicional, que es la responsable del rasgo de estatividad que los caracteriza. Así, en los verbos de la segunda clase, los más variables, la estatividad es el resultado de la construcción sintáctica y de los rasgos flexivos verbales vinculados con el tiempo y el aspecto. Las versiones analíticas de esos verbos (Nos dieron muchos sustos) presentan similitudes con sus respectivas formas sintéticas (Nos asustaron mucho) en la distribución de los argumentos, en los valores aspectuales e incluso en su carácter sistemático relativo, de ahí que también posean una interpretación psicológica. En última instancia, esa estatividad otorgada por la tipología del sujeto y la construcción específica posibilita que diferentes expresiones analíticas con elementos léxicos no especializados, es decir, no psicológicos ( $A$ mi hija le dan cosita las arañas), se reinterpreten como "cosas psicológicas".

El capítulo sexto pretende ofrecer un análisis de ciertas combinaciones [verbo + nombre psicológico] (sentir miedo, perder la alegría). Ese análisis, realizado por Elena de Miguel e inscrito en el modelo del Lexicón Generativo, atribuye al nombre psicológico la selección del verbo. Así, las combinaciones analizadas a lo largo de este trabajo parecen confirmar la hipótesis general acerca de la existencia de procesos de concordancia de rasgos sub-léxicos que legitiman las construcciones concordantes en mayor o menor medida. Precisamente, uno de esos rasgos sub-léxicos, el de [ \pm CONTENEDOR], permite desplegar la hipótesis particular del estudio, según la cual el argumento experimentante de los nombres psicológicos es siempre un contenedor (interpretación locativa), que contiene un sentimiento surgido en él 
(relación de posesión) o desencadenado en el exterior (relación de ubicación o cambio de estado provocado por un desplazamiento exterior-interior). En este sentido, el nombre psicológico se puede definir como "un contenido (el sentimiento) (con)tenido en un contenedor (el experimentante) que reúne los valores de locación y posesión”. Esta definición queda confirmada por el hecho de que los verbos más frecuentes en las combinaciones analizadas sean tener, sentir y llenar.

El séptimo y último capítulo trata de probar la existencia de relaciones gramaticales, especialmente semántico-aspectuales, entre nombres y adjetivos psicológicos vinculados morfológicamente (derivación semántica). Para ello, la autora del trabajo, Begoña Sanromán Vilas, lleva a cabo un análisis dentro de la Lexicología explicativa y combinatoria acerca de las características semántico-aspectuales, morfosintácticas y combinatorias de los adjetivos psicológicos con el fin de averiguar si es posible establecer esas correlaciones. La hipótesis del estudio descansa en la idea de que muchas de las características de estos adjetivos son heredadas de la semántica de los nombres. Un nombre psicológico (amor, irritación) denota "sentimiento" acompañado de dos participantes -el experimentador y el objeto/ causa del sentimiento-, de modo que un adjetivo psicológico es aquel que se refiere a las cualidades o propiedades de los participantes de la situación emocional (amantelamado, irritado/irritante/irritable). Teóricamente, a partir del sentido de cada nombre psicológico, pueden formarse al menos cuatro adjetivos, dos referidos al experimentador y dos referidos al objeto/causa del sentimiento. En la práctica, sin embargo, las correspondencias no son tas estrictas, las correlaciones son débiles. A pesar de esto último, las tendencias manifestadas por los adjetivos muestran la posibilidad de desarrollar una teoría conjunta capaz de explicar el comportamiento de los predicados psicológicos en su totalidad.

En definitiva, el libro reseñado se articula en torno a un objeto de estudio lingüístico concreto: los predicados de tipo psicológico en español. A través de siete diversas contribuciones, precedidas de una introducción muy clarificativa, se ofrece un panorama representativo de la problemática general que suscita esta clase de predicados. A pesar de la diversidad metodológica que caracteriza al volumen, la idea general que se desprende es la consideración unitaria de las diferentes construcciones gramaticales de carácter psicológico (verbos-predicados, nombres y adjetivos), ya que se constatan múltiples y significativas correlaciones entre ellas. Se trata de un planteamiento realmente interesante para el ámbito de la lingüística hispánica. 